\title{
The role of logistics industry in the sustainable economic development of Southeast Asian countries
}

\section{Hong Anh Thi Nguyen ${ }^{\text {* }}$}

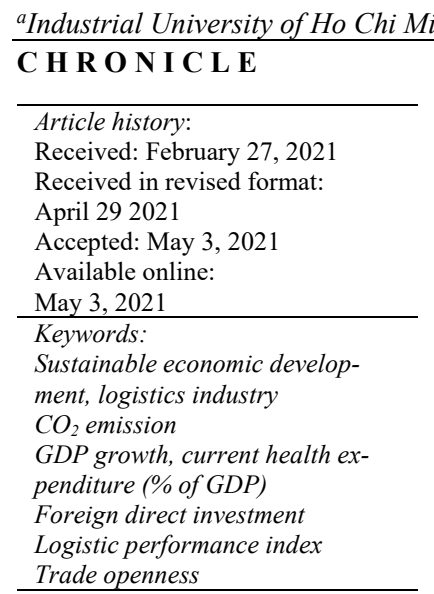

C 2021 by the authors; licensee Growing Science, Canada

\section{Introduction}

Over the years, the growing interest has been observed in influencing the environmental, social, and financial-economic activities, whose influence in the economy can be stretched to the macro level, encouraging the interest of government towards implementing some important policies and procedures to mitigate the environmental impact and to preserve the resources for making a useful contribution towards increasing economic value and GDP of the country (Liu, 2016). In this regard, the industry of logistics has gained huge attention in the previous literature due to its disadvantages and advantages for environmental performance and economic growth of the countries. The logistics industry, which displayed huge growth over the years, is now regarded as the lifeblood of economies, as all the activities that come under logistic industry plays a pivotal role for the trade and production sector (Piecyk \& Björklund, 2015). As per the general view, logistics portrays the overall flow of information flow from the source of raw material to the last point where the product is consumed, strategizing and managing this whole process both in a low-cost and productive manner through inventory and storage facilities. In this regard, logistics involve different types of services ranging from custom clearance, transportation, handling, storage, packaging, insurance, inventory and stock management, customer related services and customer relationship management (Li, Zhao \& Zhao, 2015). Many logistics firms have started to implement different ecological practices in their logistics operations to accomplish social and economic advantages without side-lining the importance of environmental sustainability. As per the report of WHO (2017), the number of people around the world who die due to air pollution on a yearly basis is more than 2.1 million, whereas Asian region is considered to be one of the most polluted areas in the world (Khan, 2019). As per the same study, the logistic sector is highly dependent on fossil fuel and also accounted for consuming $96 \%$ of its energy needs. Therefore, transport and logistic sectors have major contributions towards carbon emissions. In this regard, the concept of green logistics has gained huge prominence in the corporate world, as it promises to eliminate the negative impact of logistics on environmental and * Corresponding author.

E-mail address: nguyenthihonganh@iuh.edu.vn (H. A. T. Nguyen)

(C) 2021 by the authors; licensee Growing Science, Canada doi: $10.5267 /$ j.ac. 2021.5 .001 
social sustainability without compromising on efficiency and profitability of logistics operations. The adaptation of green practices in supply chain and logistics operations emphasises on reducing waste for achieving better environmental performance, while such practices also lead towards enhancing efficiency of performance and operations, and also towards cost reduction.

According to Lee, Kwon and Ruan (2019), the implication of logistics to resolve different issues that revolve around environmental sustainability have started to gain importance from the 1980s. On the other hand, many academicians have also identified the huge potential of logistics for environmental assessment of transport systems, product's recycling processes, minimisation and controlling of environmental pollution, resource-saving and energy processes. Moreover, the emergence of green logistics has particularly gained huge importance for some major megacities, as such cities are more prone to environmental problems. Apart from that, the logistic sector has also been recognised for making a valuable contribution towards the sustainable economic development of the countries. Despite the fact that the importance of the logistic industry has been widely recognised in terms of its contribution to economic development, there is still found to be a lack of researchers that examined the role of the logistic sector on sustainable economic development. Particularly, in the context of Southeast countries, where environmental issues have become one of the major problems of the country. Hence, the core objective of this study is to investigate the role of logistic industry on sustainable economic development of Southeast countries.

\section{Literature Review}

It has been studied that Logistics Performance Index (LPI) which is being represented by the data collected from the World Bank plays a vital role for the logistics and economic growth of the country as well as the policies that supports the economic growth (Duzbaievna Sharapiyeva, Antoni, \& Yessenzhigitova, 2019). Another aspect which has been studied is that the Composite indexes, which includes the LPI, contributes for the policymakers in order to make their decisions based upon the facts and figures (Khan, et al., 2017). In addition to that, it has also been observed that in the year of 2014, 15 out of 28 states of EU secured their position in the list of top 30 countries LPI all over the world (La \& Song, 2019). However, it has also been observed that there are some of the developing countries which have secured their position in the list such as Malaysia, China, UAE and South Africa. According to the study of Karaduman, et al. (2020), it has been observed that transportation plays an intermediary role in order to facilitate the trade flows to maintain the global supply chain. However, in this regard many of the shipping companies have realised that their transportation process has been contributing significantly to the environment in a negative manner. Therefore, considering the fact, these companies have started reducing their carbon emission rate so that they would be able to make their business environment friendly. In the light of the study which has been conducted by Mariano, et al. (2017), it has been observed that the increased rate of carbon emission has significantly affected the global environment in various aspects. Therefore, it has become clear that in case, the authorities would be neglecting this aspect in order to further enhance their policies, there would be a greater probability of bearing the losses for the global environment. Based upon the review of the related literature, the researcher has developed the first hypothesis of the study where the impact of LPI over $\mathrm{CO}_{2}$ emission was checked with the help of relevant tests.

\section{$\mathrm{H}_{1}$ : There is a significant impact of LPI on $\mathrm{CO}_{2}$ emission}

As per the study of Sharif Ali, Razman, and Awang, (2020), it has been observed that the GDP is one of the aspects that is necessary to be considered while assessing the economic condition of any country. This is mainly due to the reason that there are a number of aspects that are associated with the GDP of a country; therefore, it is evident that a country having a higher rate of GDP would be economically stable than the others. In this regard, it is also necessary to mention that the GDP only includes the production of the products within the boundaries of a country (LEMMA, 2019). This makes it clear that if a country has been producing its products outside their country, the production would be the part of that particular country where it is being produced. Therefore, the second hypothesis was developed by the help of previous studies where the relation between LPU and GDP growth was studied. In the second hypothesis, the researcher has tested the impact of LPI over GDP growth.

\section{$\mathbf{H}_{2}$ : There is a significant impact of LPI on GDP growth}

Current health expenditure refers to the expenses that a government has to bear for their people. In such a case, it is necessary to mention that a country that is economically strong would definitely be having sufficient infrastructure and would be able to facilitate the public (Jeong et al., 2019). Therefore, the countries where the current health expenditure is higher, there is a greater probability that their people would be having a longer life expectancy rate. Another aspect which has been observed is that the current health expenditure has a significant importance over the economic condition of a country which is mainly due to the reason that the countries that are having financial capacities are spending over it (Liu, Hsu, \& Huang, 2010). On the other hand, there are some of the countries where the financial position of the country is quite strong, still their current health expenditure does not meet the expected level as per their population and capabilities (Bryant, et al., 2004). Analysing the importance over current health expenditure over the economic condition of a country, the researcher has investigated the impact of LPI over the current health expenditure.

\section{$\mathbf{H}_{3}$ : There is a significant impact of LPI on Current Health Expenditure (\% of GDP).}


It has been observed during the past few decades that the role of foreign direct investment (FDI) has been increased in the total capital flows (Alvarado, Iniguez, \& Ponce, 2017). In addition to that, it has also been observed that post 1998, most of the capital cash flows were being done by the help of FDI. This change in capital flow composition was synchronous with a shift in focus among policymakers in developed countries to attract more FDI, particularly after the debt crisis of the 1980s and the recent turmoil in emerging economies (Solarin \& Al-Mulali, 2018). The justification for intensified efforts to draw more FDI derives from the assumption that FDI has many beneficial consequences that include efficiency growth, technological transition, and adoption of new technologies, management expertise and domestic business know-how, recruitment of workers, foreign supply networks and market access. Therefore, in this study three hypotheses have been developed separately for the checking the impact of FDI over the $\mathrm{CO}_{2}$ emission, GDP growth and Current Health Expenditure.

\section{H4: There is a significant impact of FDI on $\mathrm{CO}_{2}$ emission.}

Hs: There is a significant impact of FDI on GDP growth.

H6: There is a significant impact of FDI on Current Health Expenditure (\% of GDP).

It has been studied that the impact of a variety of trade openness (TOP) initiatives have a great influence over the economic sustainability of a country (Shahbaz, et al., 2017). In addition to that, it has also been studied that the TOP is one of the indicators to identify how dedicated a nation is to the world trading mechanism (Kurniawan \& Managi, 2018). Furthermore, the study conducted by Keho (2017) contributed that TOP is being calculated by the ratio of the number of exports and imports to the GDP. In addition to that, it has also been studied that trade openness is a concept which is being derived by the policies of a country for dealing the trade between countries (Awokuse, 2008). There are some of the countries where the percentage of tax which is being charged by the country for the imports and exports is lower and they are also allowing the traders to enter the trading business with lower amounts of investments. On the other hand, some of the countries have fixed a high amount of tax over imports which has made it difficult for their people to get into the trading business (Haddad, et al., 2013). Therefore, it has become clear that TOP has a great role for the economic condition of a country based upon which the below three hypotheses have been made where the researcher has investigated the impact of TOP over $\mathrm{CO}_{2}$ emission, GDP growth and Current Health Expenditure.

\section{H7: There is a significant impact of TOP on $\mathrm{CO}_{2}$ emission.}

H8: There is a significant impact of TOP on GDP growth.

H9: There is a significant impact of TOP on Current Health Expenditure (\% of GDP).

\section{Theoretical Framework}

The endogenous growth theory can be viewed in the context of sustainable economic development, in which the diffusion of technological change and innovation is clearly demonstrated as the major driving force for economic growth (Pan and Ngo, 2016). The endogenous growth theory holds the view that economic growth of any country is the outcome of endogenous and not the external forces. Moreover, in accordance with the study of Cozzi (2017), endogenous theory also assumes that investments in knowledge, innovation and human capital can make the significant contribution towards the economic growth of any country. On the other hand, concerning sustainable development, endogenous growth theory emphasises on the contribution of innovation and technologies to the situation under which the economic development can be sustained by the environment and resources. Similarly, according to Mulder and Van Den Bergh (2001), endogenous growth theory postulates that economic growth is mainly the result of internal forces instead of external forces. Moreover, this theory argues that the improvement in productivity can only be achieved through innovations and more human capital investments from private sector institutions and government. Therefore, based on this theory, companies are required to pay special attention towards making technological advancements in order to achieve high productivity.

\section{Research Methods}

\subsection{Data Collection Process}

In this study, researchers have collected historical secondary data to examine the role of the logistic industry in the sustainable economic development of Southeast Asian countries. The nature of the research topic demands a comprehensive amount of data related to different components of sustainable economic development and the performance of the logistic sector, which could not have been possible through using primary sources of data collection. Therefore, the use of secondary sources has been made in this study to collect the data on different variables of this study. The data has been obtained from the World Bank website, which is one of the most useful and authentic open data websites. The data has been collected from the year 2007 to 2018. Moreover, the data of all the Southeast countries have been gathered, which include Indonesia, Thailand, Singapore, Vietnam, Malaysia, Philippines, Myanmar, Cambodia, Laos, Brunei, and Timor-Leste. There was sufficient data available on each country, therefore researchers have selected all the Southeast countries into the investigation. The variables 
on which the data has been collected includes logistics performance index, $\mathrm{CO}_{2}$ emission, Real GDP, current health expenditure $(\%$ of GDP, FDI, and trade openness. The data on all these variables have allowed the researcher to identify the association between the logistic sector and sustainable economic development.

\subsection{Research Design}

Research design is regarded as the overall research strategy that researchers select to integrate different aspects of the study in a more logical and coherent way (Rahi, 2017). The selection of appropriate research design is largely depending on the type of research questions to be answered, and the nature of the study. Therefore, researchers have ensured to make a right selection of research design on the basis of study nature. According to Rutberg and Bouikidis (2018), the two of the most widely used research designs are quantitative and qualitative. In qualitative research designs, researchers look to incorporate human interests, perceptions and concepts into the study through collecting the data from survey questionnaires, interviews etc. On the other hand, quantitative research design emphasises on gathering more fact-based data to identify association between different variables of the study (Morgan, 2017). The researcher design used in this study is quantitative, which is mainly due to the study nature, as this study demands more fact-based and numerical data to understand the role of the logistic sector on the sustainable economic development of Southeast Asian countries. Therefore, the use of quantitative research design was considered as a more suitable approach for this study, as it allows the researcher to analyse the data in terms of quantifiable figures and numbers.

\subsection{Data Analysis Technique}

To test the model and for accomplishing the main objective of this study, researchers have feasible generalised least square method (FGLS). FGLS is considered as an effective statistical technique that is used for estimating the multiple linear regression coefficients and also their covariance. The key reason behind using FGLS in this study is due to the fact that there were some issues associated with serial and heteroskedasticity in the initial assessment. As per the study of Difeto et al. (2018), FGLS offered precise results while identifying the regression in the presence of heteroskedastic errors as opposed to Ordinary Least Squares (OLS). Hence, the use of FGLS has been considered as a more appropriate approach for this study for analysing secondary quantitative data.

\section{Results and Analysis}

\subsection{Descriptive Statistics}

The below presented Table 1 outlines the results of descriptive statistics, which helps in analysing the statistical characteristics of the data. In accordance with the study of Fisher and Marshall (2009), descriptive statistics is probably the most effective technique to explain some of the most common features of the data used in a study. Descriptive statistics highlights some of the important measures of data including standard deviation, mean, number of total observations, and range. In descriptive statistics, researchers only emphasise on what data shows, whereas in inferential statistics not just define the data but also provide a conclusion. Some of the key values to consider in Table 1 are mean, standard deviation, and total number of observations.

Table 1

The summary of some basic statistics

\begin{tabular}{|c|c|c|c|c|c|}
\hline Variable & Observation & Mean & Std. Dev & Min & Max \\
\hline LPI & 132 & 2.864886 & .6339905 & 1.71 & 4.19 \\
\hline GDP Growth & 132 & 5.275256 & 3.17322 & -3.798649 & 14.52564 \\
\hline $\mathrm{CO}_{2}$ Emission & 132 & 118775.8 & 146978.9 & 183.35 & 563324.5 \\
\hline Current Health Expenditure (\% of GDP) & 132 & 3.675835 & 1.475803 & 1.027951 & 7.583306 \\
\hline FDI & 132 & 5.779415 & 5.828729 & -1.320522 & 28.59812 \\
\hline TOP & 132 & 123.4295 & 87.28987 & .1674176 & 437.3267 \\
\hline
\end{tabular}

In accordance with the results highlighted in table, the total number of observations taken for each variable including LPI, GDP growth, $\mathrm{CO}_{2}$ emission, current health expenditure, FDI, and trade openness is 132 . Moreover, all the observations taken in this study were from 2007 to 2018. Apart from that, table 1 also outlines the mean values of all the variables. In this regard, the average value of LPI variable is figured as 2.864886, whereas the average value of GDP growth is computed at 5.275256. Moreover, the mean value of $\mathrm{CO}_{2}$ emission is found to be 118775.8 , which depicts the average value of all the countries investigated in this study. Similarly, the average value of current health expenditure for all the studies is computed at 3.675835, whereas FDI is figured at 5.779415. Lastly, the average trade openness value of all the Southeast countries is found to be 123.4295. On the other hand, the next value highlighted in table 1 is standard deviation, which signifies the variations across the data. As per the value outlined in Table 1, LPI is found to be deviating from .6339905. Furthermore, the standard deviation of GDP growth is computed at 3.1732, which means that GDP growth will deviate from 3.173\%. Similarly, the standard deviation value of $\mathrm{CO} 2$ emission is found to be 146978.9 , which shows that $\mathrm{CO}_{2}$ emission will deviate from $146978.9 \mathrm{kt}$. As per the findings of descriptive statistics, current health expenditure will deviate from $1.47 \%$, whereas the FDI will deviate from 5.828729. Lastly, in accordance with the finding's descriptive statistics, the variable of trade openness will deviate from 87.28987. 


\subsection{Correlation}

Table 2 presents the results of correlation analysis, which depicts the association between different variables of this study. The key independent variable of this study is LPI, FDI, and TOP, whereas the dependent variable of this study includes GDP growth, current health expenditure and $\mathrm{CO}_{2}$. As per the figures highlighted in Table 2, the significant but negative association has been found between LPI and GDP growth. In contrast, the variable of LPI is found to have a significant and positive association with current health expenditure. Similarly, $\mathrm{CO}_{2}$ is also found to have a strong association with LPI. On the other hand, the variable of FDI makes a significant association with both GDP growth and current health expenditure; however, there is found to be a negative association between FDI and $\mathrm{CO}_{2}$. Lastly, as per the results of correlation analysis, trade openness is found to have an insignificant association with all the dependent variables including $\mathrm{CO}_{2}$, GDP growth and current health expenditure.

Table 2

The summary of the correlation

\begin{tabular}{|c|c|c|c|c|c|c|}
\hline & LPI & GDP Growth & Current Health Expenditure & FDI & TOP & $\mathrm{CO}_{2}$ \\
\hline LPI & 1.0000 & & & & & \\
\hline GDP Growth & $-0.2171 *$ & 1.0000 & & & & \\
\hline Current Health Expenditure & $0.1923^{*}$ & 0.0633 & 1.0000 & & & \\
\hline FDI & $0.4230^{*}$ & $0.1875^{*}$ & $0.3081 *$ & 1.0000 & & \\
\hline TOP & $0.6897^{*}$ & -0.0558 & 0.1657 & $0.7566^{*}$ & 1.0000 & \\
\hline $\mathrm{CO}_{2}$ & $0.6968^{*}$ & -0.0645 & $0.2396^{*}$ & -0.0980 & 0.0948 & 1.0000 \\
\hline
\end{tabular}

\subsection{Feasible Generalised Least Squares Model (FGLS)}

\section{Model 1}

The results of model 1 presented in Table 3 depicts the impact of all the independent variables on $\mathrm{CO}_{2}$ emission based on the data of all the countries collected in this study. In accordance with the results, LPI makes the significant and positive impact on $\mathrm{CO}_{2}$ emission [P-value $=0.000$ ]. In contrast, both the variable including FDI and TOP is found to have a significant negative impact on $\mathrm{CO}_{2}$ emission with the value of coefficient computed at -.0453799 and -.015291 respectively. This implies that increase in FDI inflows and trade openness can inversely influence $\mathrm{CO}_{2}$ emission.

Table 3

The results of the regression analysis

\begin{tabular}{llll}
\hline & Coefficient & Std. Error & Z-statistics \\
\hline LPI & 3.972448 & .1957549 & 20.29 \\
FDI & -.0453799 & .0235771 & -1.92 \\
TOP & -.015291 & .0019702 & -7.76 \\
\hline Wald chi-square & 456.77 & & 0.000 \\
\hline *Significant at $10 \% * *$ Significant at $5 \% \cdot * * *$ Significant at $1 \%$ & & 0.054 \\
\hline
\end{tabular}

*Significant at $10 \% ; * *$ Significant at $5 \% ; * * *$ Significant at $1 \%$

\section{Model 2}

Model 2 shows the impact of all the independent variables of this study on GDP growth. As shown in Table 4, the significant but negative impact of LPI has been found on GDP growth, as the value of coefficient figured at -1.252758 . In contrast, FDI is found to have a significant and positive impact on GDP growth, whereas no significant impact of TOP has been found on GDP growth of all the countries investigated in this study.

Table 4

The results of the regression analysis

\begin{tabular}{llll}
\hline & Coefficient & Std. Error & Z-statistics \\
\hline LPI & -1.252758 & .5645303 & -2.22 \\
FDI & .2610309 & .0679931 & 3.84 \\
TOP & -.0089403 & .0056817 & -1.57 \\
\hline Wald chi-square & 24.76 & & 0.026 \\
\hline
\end{tabular}

*Significant at $10 \%$;* Significant at $5 \% ; * * *$ Significant at $1 \%$

\section{Model 3}

Table 5 depicts the impact of independent variables on current health expenditure (\% of GDP).

Table 5

The results of the regression analysis

\begin{tabular}{llll}
\hline & Coefficient & Std. Error & Z-statistics \\
\hline LPI & .5578747 & .2662091 & 2.10 \\
FDI & .122219 & .0320627 & 3.81 \\
TOP & -.006167 & .0026793 & -2.30 \\
\hline Wald chi-square & 20.49 & & Probability-value
\end{tabular}

*Significant at $10 \% ; * *$ Significant at $5 \% ; * * *$ Significant at $1 \%$ 
As per the results, both the variables of LPI and FDI are found to have a significant and positive impact on current health expenditure. However, TOP makes a significant but negative impact on current health expenditure.

\section{Summary of Hypothesis}

Table 6 presents the summary of testing different hypotheses.

Table 6

The results of testing different hypotheses

\begin{tabular}{|c|c|}
\hline Hypotheses & Decision \\
\hline $\mathrm{H}_{1}$ : There is a significant impact of LPI on $\mathrm{CO}_{2}$ emission & Accepted \\
\hline $\mathrm{H}_{2}$ : There is a significant impact of LPI on GDP growth & Accepted \\
\hline $\mathrm{H}_{3}$ : There is a significant impact of LPI on Current Health Expenditure ( $\%$ of GDP) & Accepted \\
\hline $\mathrm{H}_{4}$ : There is a significant impact of FDI on $\mathrm{CO}_{2}$ emission & Accepted \\
\hline $\mathrm{H}_{5}$ : There is a significant impact of FDI on GDP growth & Accepted \\
\hline $\mathrm{H}_{6}$ : There is a significant impact of FDI on Current Health Expenditure ( $\%$ of GDP) & Accepted \\
\hline $\mathrm{H}_{7}$ : There is a significant impact of TOP on $\mathrm{CO}_{2}$ emission & Accepted \\
\hline $\mathrm{H}_{8}$ : There is a significant impact of TOP on GDP growth & Accepted \\
\hline $\mathrm{H}_{9}$ : There is a significant impact of TOP on Current Health Expenditure ( $\%$ of GDP) & Rejected \\
\hline
\end{tabular}

\section{Discussion}

The primary goal of this study has been to analyse the role of logistic industry in the sustainable economic development in the context of Southeast Asian countries. In this regard, the independent variables of this study include trade openness, logistics performance index, and foreign direct investment. The impact of all these variables have been examined on $\mathrm{CO} 2 \mathrm{emission}$, current health expenditure and GDP growth. The findings of this study confirm the significant and positive impact of LPI on $\mathrm{CO} 2$ emissions and current health expenditure (\% of GDP). However, LPI is found to have a significant but negative impact on GDP growth. This result is found to be contradicting with the study of Uca, Civelek and Çemberci (2015), in which positive impact of LPI has been found on GDP growth. On the other hand, the findings of this study reveal the significant and positive impact of FDI on both current health expenditure and GDP, whereas FDI is found to have a significant but negative impact on $\mathrm{CO}_{2}$ emission. This is also found to be consistent with the study of Huang et al. (2019), in which negative association has been found between FDI and $\mathrm{CO}_{2}$ emission. Lastly, in accordance with the findings of this study, the variable of TOP makes a significant but negative impact on both current health expenditure and $\mathrm{CO} 2$ emission. However, TOP is found to have an insignificant impact on GDP growth.

\section{Conclusion}

The analysis and outcomes of this study portrays the huge significance of the logistics industry for the sustainable economic development of Southeast Asian countries. The primary goal of this study was to identify the impact of the logistic industry on different components of sustainable economic development in the context of Southeast Asian countries. For that purpose, the variable of logistic industry has been measured through three different variables, which include FDI, LPI and TOP. On the other hand, the component of sustainable economic development was measured through GDP growth, $\mathrm{CO}_{2}$ emission, and current health expenditure. In this regard, GDP growth has been taken as an economic indicator, whereas the variable of $\mathrm{CO}_{2}$ emission and current health expenditure was taken as an environmental and social indicator. To accomplish the key objective of this study, the collection of secondary quantitative data has been made from the Word Bank website. The data of all the Southeast Asian countries have been collected from the time period of 2007 to 2018. Moreover, researchers employ the technique of descriptive statistics, correlation analysis, and feasible generalised least square model to analyse the collected data. The findings of this study reveal the significant and positive influence of LP1 on current health expenditure (\% of GDP) and CO2 emission, whereas LP1 makes the negative impact on GDP growth. Furthermore, the findings reveal the positive and significant impact of FDI on GDP growth and current health expenditure; however, as per the findings, FDI makes a significant but negative impact on $\mathrm{CO}_{2}$ emission. Lastly, the outcomes of this study also confirm the negative and significant impact of TOP on both $\mathrm{CO}_{2}$ emission and current health expenditure, whereas no significant impact of TOP has been found on GDP growth.

\section{Limitation and Future Implications}

The major limitation of this study is that there is a lack of qualitative data in terms of identifying the relationship between the identified factors of the study. In addition to that, it is also necessary to mention that there is a limited scope of this study over the Southeast Asian countries. Therefore, this makes it clear that there are some of the aspects which can be used by the future researchers in their respective studies to fill the research gap. However, the most effective method to fill the research gap would be the inclusion of qualitative data in the future study in order to identify that what are the perceptions of the policy makers and the business in terms of LPI, FDI and TOP relationship with the $\mathrm{CO}_{2}$ emission, GDP and Current Health Expenditures. 


\section{References}

Alvarado, R., Iniguez, M., \& Ponce, P. (2017). Foreign direct investment and economic growth in Latin America. Economic Analysis and Policy, 56, 176-187.

Awokuse, T.O. (2008). Trade openness and economic growth: is growth export-led or import-led?. Applied economics, 40(2), pp.161-173.

Bryant, J., Teasdale, A., Tobias, M., Cheung, J., \& McHugh, M. (2004). Population ageing and government health expenditures in New Zealand, 1951-2051 (No. 04/14). New Zealand Treasury Working Paper.

Cozzi, G. (2017). Endogenous growth, semi-endogenous growth... or both? A simple hybrid model. Economics Letters, 154, pp.28-30.

Difeto, M., van Eyden, R., Gupta, R., \& Wohar, M.E. (2018). Oil price volatility and economic growth: Evidence from advanced OECD countries using over one century of data (No. 201813).

DuzbaievnaSharapiyeva, M., Antoni, A., \& Yessenzhigitova, R. (2019). The impact of port transport-logistics infrastructure and lpi for economic growth: On the example of landlocked countries. Pomorstvo, 33(1), 63-75.

Fisher, M.J., \& Marshall, A.P. (2009). Understanding descriptive statistics. Australian Critical Care, 22(2), 93-97.

Haddad, M., Lim, J.J., Pancaro, C., \& Saborowski, C. (2013). Trade openness reduces growth volatility when countries are well diversified. Canadian Journal of Economics/Revue canadienned'économique, 46(2), 765-790.

Huang, Y., Chen, X., Zhu, H., Huang, C., \& Tian, Z. (2019). The heterogeneous effects of FDI and foreign trade on CO2 emissions: evidence from China. Mathematical Problems in Engineering, 2019.

Jeong, H.S., Shin, J.W., Moon, S.W., Choi, J.S., \& Kim, H. (2019). 2018 Current Health Expenditures and National Health Accounts in Korea. Health Policy and Management, 29(2), pp.206-219.

Karaduman, H.A., Karaman-Akgül, A., Çağlar, M., \& Akbaş, H.E. (2020). The relationship between logistics performance and carbon emissions: an empirical investigation on Balkan countries. International Journal of Climate Change Strategies and Management, 12(4).

Keho, Y. (2017). The impact of trade openness on economic growth: The case of Cote d'Ivoire. Cogent Economics \& Finance, 5(1), 1332820.

Khan, S.A.R. (2019). The Effect of Green logistics on Economic growth, Social and Environmental sustainability: An Empirical study of Developing countries in Asia.

Khan, S.A.R., Qianli, D., SongBo, W., Zaman, K., \& Zhang, Y., 2017. Environmental logistics performance indicators affecting per capita income and sectoral growth: evidence from a panel of selected global ranked logistics countries. Environmental Science and Pollution Research, 24(2), 1518-1531.

Kurniawan, R., \& Managi, S. (2018). Coal consumption, urbanization, and trade openness linkage in Indonesia. Energy Policy, 121, 576-583.

La, K.W., \& Song, J.G. (2019). An Empirical Study on the Effects of Export Promotion on Korea-China-Japan Using Logistics Performance Index (LPI). Journal of Korea Trade, 23(7), 96-112.

Lee, P.T.W., Kwon, O.K., \& Ruan, X. (2019). Sustainability challenges in maritime transport and logistics industry and its way ahead.

LEMMA, Y., 2019. FACTORS AFFECTING SHARE OF TAX REVENEUE IN GROWTH DOMESTIC PRODUCT (GDP) OF ETHIOPIA (Doctoral dissertation, st.mary's University).

Li, A., Zhao, P., \& Zhao, Y. (2015). Empirical analysis on the relationship between logistics industry and economic growth in Xuzhou. Management \& Engineering, 20(1), 80-85.

Liu, C., Hsu, S., \& Huang, Y.K. (2010). The determinants of health expenditures in Taiwan: modeling and forecasting using time series analysis. Journal of Statistics and Management Systems, 13(3), 515-534.

Liu, X. (2016). The impact of logistics costs on the economic development: The case of Thailand. Business and Public Administration Studies, 10(1), 37-42.

Mariano, E.B., Gobbo Jr, J.A., de Castro Camioto, F., \& do Nascimento Rebelatto, D.A. (2017). CO2 emissions and logistics performance: a composite index proposal. Journal of Cleaner Production, 163, 166-178.

Morgan, D.L. (2017). Research design and research methods. Integrating qualitative and quantitative methods: A pragmatic approach. London, England: SAGE.

Mulder, P., \& Van Den Bergh, J.C. (2001). Evolutionary economic theories of sustainable development. Growth and Change, 32(1), 110-134.

Pan, W.H., \& Ngo, X.T. (2016). Endogenous growth theory and regional performance: The moderating effects of special economic zones. Communist and Post-Communist Studies, 49(2), 113-122.

Piecyk, M.I., \& Björklund, M. (2015). Logistics service providers and corporate social responsibility: sustainability reporting in the logistics industry. International Journal of Physical Distribution \& Logistics Management, 45(5).

Rahi, S. (2017). Research design and methods: A systematic review of research paradigms, sampling issues and instruments development. International Journal of Economics \& Management Sciences, 6(2), 1-5.

Rutberg, S., \& Bouikidis, C.D. (2018). Focusing on the fundamentals: A simplistic differentiation between qualitative and quantitative research. Nephrology Nursing Journal, 45(2), 209-213.

Shahbaz, M., Nasreen, S., Ahmed, K., \& Hammoudeh, S. (2017). Trade openness-carbon emissions nexus: the importance of turning points of trade openness for country panels. Energy Economics, 61, 221-232. 
Sharif Ali, S.S., Razman, M.R., \& Awang, A. (2020). The nexus of population, growth domestic product growth, electricity generation, electricity consumption and carbon emissions output in Malaysia. International Journal of Energy Economics and Policy, 10(3), 84-89.

Solarin, S.A., \& Al-Mulali, U. (2018). Influence of foreign direct investment on indicators of environmental degradation. Environmental Science and Pollution Research, 25(25), 24845-24859.

Uca, N., Civelek, M.E., \& Çemberci, M. (2015). The effect of the components of logistics performance index on gross domestic product: conceptual model proposal. Eurasian Business \& Economics Journal, 1, 86-93.

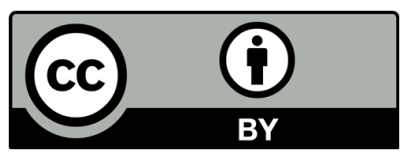

(C) 2021 by the authors; licensee Growing Science, Canada. This is an open access article distributed under the terms and conditions of the Creative Commons Attribution (CC-BY) license (http://creativecommons.org/licenses/by/4.0/). 